\title{
The net energy content of dried sugar-beet pulp and of sucrose when fed to lactating cows
}

\author{
A. J. H. van Es, H. J. Nijkamp and J. E. Vogt \\ Department of Animal Physiology, Agricultural University, Wageningen, \\ the Netherlands
}

Received: 30 November 1970

\section{Summary}

Three energy balance experiments were performed, each with 6 lactating cows. In the first experiment in two trials the net energy contents of dried sugar-beet pulp and barley when used in a mixed ration were compared. This was repeated in the second experiment using maize instead of barley. In both cases about half of the dry matter of the ration consisted of hay, the other half was a concentrate mixture containing some $40 \%$ barley, maize or sugar-beet pulp. There was no significant proof or indication that the digested energy of barley or maize was utilized better or worse for maintenance and production than the digested energy of pulp. The results suggest that in the starch equivalent system the same value number should be used for pulp, barley and maize. In the third experiment $8 \%$ sucrose in the concentrates of a mixed ration was exchanged for $8 \%$ starch. Here also the digested energy of the two rations was utilized equally efficiently.

\section{Introduction}

While preparing a revised edition of the Dutch feeding table for farm animals (Anon., 1970) several experiments were initiated in fields where information was poor or conflicting. One of those fields concerned the value number used in the starch equivalent system of Kellner in the case of dried sugar-beet pulp and of sucrose. The starch equivalent content of dried sugar-beet pulp was measured by Kellner in three balance trials, each with one steer, and by Fingerling in one trial. Dijkstra (1960) derived from their results the following value numbers: 76.6, 71.6, 79.9 and 78.4. Schiemann (1958) concluded that in Kellner's trials the standard deviations were 8, 22 and $11 \%$, respectively.

Also the number of balance trials performed with sucrose up to 1950 was small, here again the results were variable: Kellner $1.7 \mathrm{kcal}$ net energy/g; Fingerling 2.0 $\mathrm{kcal} / \mathrm{g}$ compared to $2.4 \mathrm{kcal} / \mathrm{g}$ for starch. (See Nehring et al., 1965, p. 265.) Nehring et al. (1965) could confirm the value of Fingerling, but individual results showed more variation than in case of most other feeds. The high sucrose levels $(27 \%)$ which in the balance trials had to be used had a negative influence on the digestibility of the basal ration. In their feeding system (Nehring et al., 1969) based on a large number of balance trials with various feedstuffs including dried sugar-beet pulp they do not treat pulp differently from barley or maize except for a small correction for the pre- 
sence of sucrose (a subtraction of $0.15 \mathrm{kcal}$ net energy per $\mathrm{g}$ sucrose present, amounting to about $0.5 \%$ of the total net energy content of the pulp).

The high crude fibre content of pulp is often thought to be the cause of the low value number. It should, however, be remembered that this crude fibre is highly digestible for pigs (Anon., 1970). Its composition differs considerably from crude fibre of other feedstuffs.

\section{Considerations which led to the experimental scheme}

Table 1 shows the average composition of dried sugar-beet pulp, barley and maize as given by the CVB-table (Anon., 1970). Pulp mainly differs in composition from the other feedstuffs because of its higher content of crude fibre and digestible crude fibre. The contents of organic matter of the three feeds hardly differ. The contents of digestible organic matter (DOM) and of total digestible nutrients (TDN) are somewhat higher for maize. This is due to the fact that maize contains more $\mathrm{N}$-free extract which also has a higher digestibility $(94 \%)$ than the $\mathrm{N}$-free extract of pulp $(92 \%)$ and barley $(90 \%)$ and than the crude fibre of pulp $(82 \%)$. Due to the higher fat content maize contains slightly more TDN per $\mathrm{g}$ DOM than the other two feeds. Pulp also has a higher content of sucrose $(8.7 \%$ ). Sucrose contains $5 \%$ less energy than, for example, starch. On an energy basis this $8.7 \%$ sucrose, therefore, is equivalent to $8.3 \%$ starch, which means for the total feedstuff a correction of only $0.4 \%$. Barley and maize usually contain only 1 or $2 \%$ di- and monosaccharides.

In the TDN feeding system it is assumed that the TDN of all kinds of concentrates are utilized for maintenance and production equally efficiently irrespective of their origin. The content of TDN is strongly, linearly correlated to the content of digestible and metabolizable energy (DE and ME) of the feedstuff (Jakobsen, 1969). To test the assumption it could be measured if lactating cows fed rations with either pulp, barley or maize utilize the $\mathrm{DE}$ or ME of these rations equally efficiently.

According to the new feeding system of Nehring et al. (1969) the net energy content for fattening steers of concentrates of various origin can be computed by multi-

Table 1. Composition of dried sugar-beet pulp, barley and maize in $\mathrm{g}$ per $100 \mathrm{~g}$ (Anon., 1970).

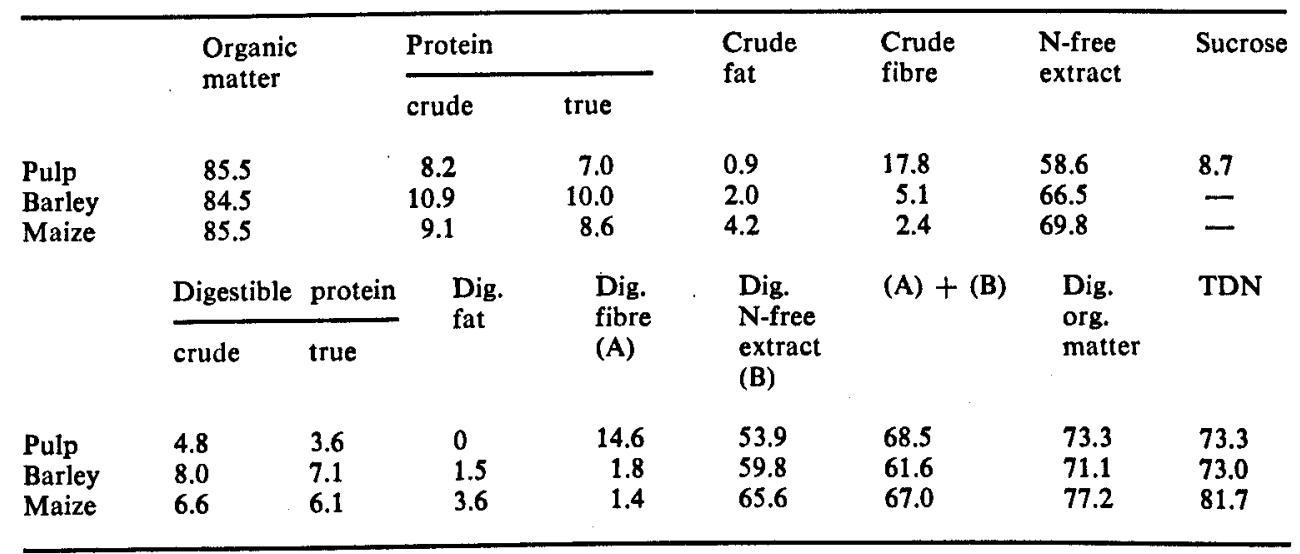


plying their contents of digestible nutrients - crude protein, crude fat, crude fibre and $\mathrm{N}$-free extract - by $1.71,7.52,2.01$ and 2.01 , respectively, provided that for sucrose a slight correction is applied of $-0.15 \mathrm{kcal} / \mathrm{g}$.

This net energy value, in their opinion, could also be used for concentrates in rations of lactating cows. Net energy is the result of the conversion of DE into ME and of $\mathrm{ME}$ into net energy. To test if the value computed so is relatively correct for pulp, barley and maize, it could be studied whether or not for each of the three feeds when used in rations for lactating cows one gram of DOM of the three rations contains the same amount of DE and whether or not this DE is equally efficiently converted into $\mathrm{ME}$ and net energy.

According to the modified Kellner feeding system in the Netherlands (Anon., 1970) the content of starch equivalent of concentrates of various origin can be computed by multiplying the contents of the digestible nutrients - true protein, crude fat, crude fibre, N-free extract - by $0.94,3.0,1.0$ and 1.0 , respectively, subtracting $0.24 \times$ the content of sucrose in feeds like pulp or, for other feeds, if they contain more than $10 \%$, and multiplying the result with a value number, varying from one kind of food to another. Also in this case the correctness of this feeding system could be tested as proposed for Nehring's system.

The feeding value of sucrose and of starch when used in rations of lactating cows could also be compared in this way. Attention, however, is to be paid to the percentage of sucrose in the ration. Dairy rations seldom contain high sucrose levels. Therefore it is more interesting to study its feeding value at low levels. This also excludes the possible occurrence of digestive disturbances as met by Kellner and Nehring. Broster et al. (1970) used rations with about 20-25\% sucrose in the concentrate mixture fed to dairy cows. It markedly changed the production of volatile fatty acids in the rumen. The positive effect of sucrose on milk yield was much smaller than the effect of a comparable addition of concentrates. We decided to use $8 \%$ sucrose in the concentrate mixture, also considering that dairy concentrate rations hardly ever contain more than $8 \%$ di- and monosaccharides.

For all the proposed tests it holds true that it will be easier to detect small differences between pulp and barley, or between sucrose and starch at higher contents of these feedstuffs in the rations. Rations for lactating cows, however, contain hay, and their concentrates probably should not contain more than $40 \%$ of one ingredient, such as pulp, barley or maize. This means that the total ration will contain only about $25 \%$ and its DOM only about $30 \%$ pulp, barley or maize. All differences between rations if only due to one of these feeds thus should be multiplied by 4 or 3.3 which also applies to their errors.

In the case of sucrose and starch the situation is even worse. A level of $8 \%$ sucrose or starch in the concentrate mixture means a level of about $4 \%$ in the total ration or about $6 \%$ in its DOM due to the high digestibility of sucrose and starch. It will, therefore, be necessary to reduce the influence of errors as much as possible, which can be done by doing the comparisons in reversal trials, by using not too few cows and by repeating the trials if possible.

\section{Methods}

In each of the three reversal trials 6 lactating Friesian cows, age 4-12 years, were used. In the first part of the first trial 3 cows got a ration with dried sugar-beet 
Table 2. Rations.

a. Pulp and barley rations in Trials $R 115$ and $R 116$

1. $50 \%$ premix $+10 \%$ molasses $+40 \%$ dried sugar-beet pulp.

2. $50 \%$ premix $+10 \%$ molasses $+40 \%$ barley.

The premix contained; $50 \%$ maizegluten feed, $5 \%$ linseed, $15 \%$ rapeseed meal, $10 \%$ soybean, $5 \%$ soybean meal, $8.8 \%$ coconut expeller, $6 \%$ minerals and vitamins $\mathrm{A}$ and $\mathrm{D}_{3}$.

The pulp and barley contained $81.2 \%$ and $82.3 \%$ organic matter, respectively.

b. Pulp and maize rations in Trials $R 119$ and $R 120$

1. $50 \%$ premix $+10 \%$ molasses $+40 \%$ dried sugar-beet pulp.

2. $50 \%$ premix $+10 \%$ molasses $+40 \%$ maize.

The premix had the same composition as in the preceding trials. The pulp and maize both contained $83.2 \%$ organic matter.

c. Sucrose and starch rations in Trials $R 121$ and $R 122$

1. $80 \%$ premix $+12 \%$ soybean meal $+8 \%$ sucrose.

2. $80 \%$ premix $+12 \%$ soybean meal $+8 \%$ maize starch.

The premix contained : $34.5 \%$ maize, $20 \%$ sorghum, $10 \%$ sugar-beet pulp, $15 \%$ wheatbran, $15 \%$ maizegluten meal, $5.5 \%$ minerals and vitamins $\mathrm{A}$ and $\mathrm{D}_{3}$.

The sucrose and starch contained $100 \%$ and $87.9 \%$ organic matter, respectively.

pulp ( $40 \%$ of the concentrate mixture) and the others the same ration but with barley instead of pulp. In the second part the rations were reversed. The second reversal trial had the same design as the first but corn replaced the barley. In the first part of the last trial 3 cows received a ration with $8 \%$ sucrose in the concentrate mixture and the other three the same ration with starch instead of sucrose. Details about the rations are given in Table 2.

Energy and nitrogen balances of the cows were determined during a 14 days' experimental period which followed after a 12 days' preliminary period. In each experimental period faeces and urine were collected separately and 2 or 348 -hour respiration trials were performed with each animal to obtain data on methane and carbon dioxyde production and oxygen consumption. From these data the heat production of the cows was derived using both the Brouwer equation and the $\mathrm{CN}$-balance method (see: van Es, 1961 and 1966).

During the first part of the first reversal trial the cows ate only $3 / 4$ of their hay due to high temperatures in the digestion stall.

In the beginning of its second part one of the cows had to be removed from the experiment because of troubles with her legs.

\section{Results and discussion}

The comparison between sugar-beet pulp and barley (Trials $R 115$ and $R$ 116; see Table 3)

In the trial with pulp 1 gramme DOM contained $4.49-4.53 \mathrm{kcal}$ DE and in the trial with barley $4.54-4.63 \mathrm{kcal}$. The difference obviously is small. It might have been due to the higher fat and lower sucrose content of barley. In the first part ( $R$ 115) $86.6 \%$ of the $\mathrm{DE}$ was converted into $\mathrm{ME}$ for pulp versus $84.2 \%$ for barley. In the second part ( $R$ 116) these figures were $86.4 \%$ for both rations. In the first part the cows left considerable feed rests, especially those on the barley ration. For this reason more value has to be attached to the figures of the second part than to those of the first part. To be able to compare the utilization of the $\mathrm{ME}$ of the rations first a correc- 


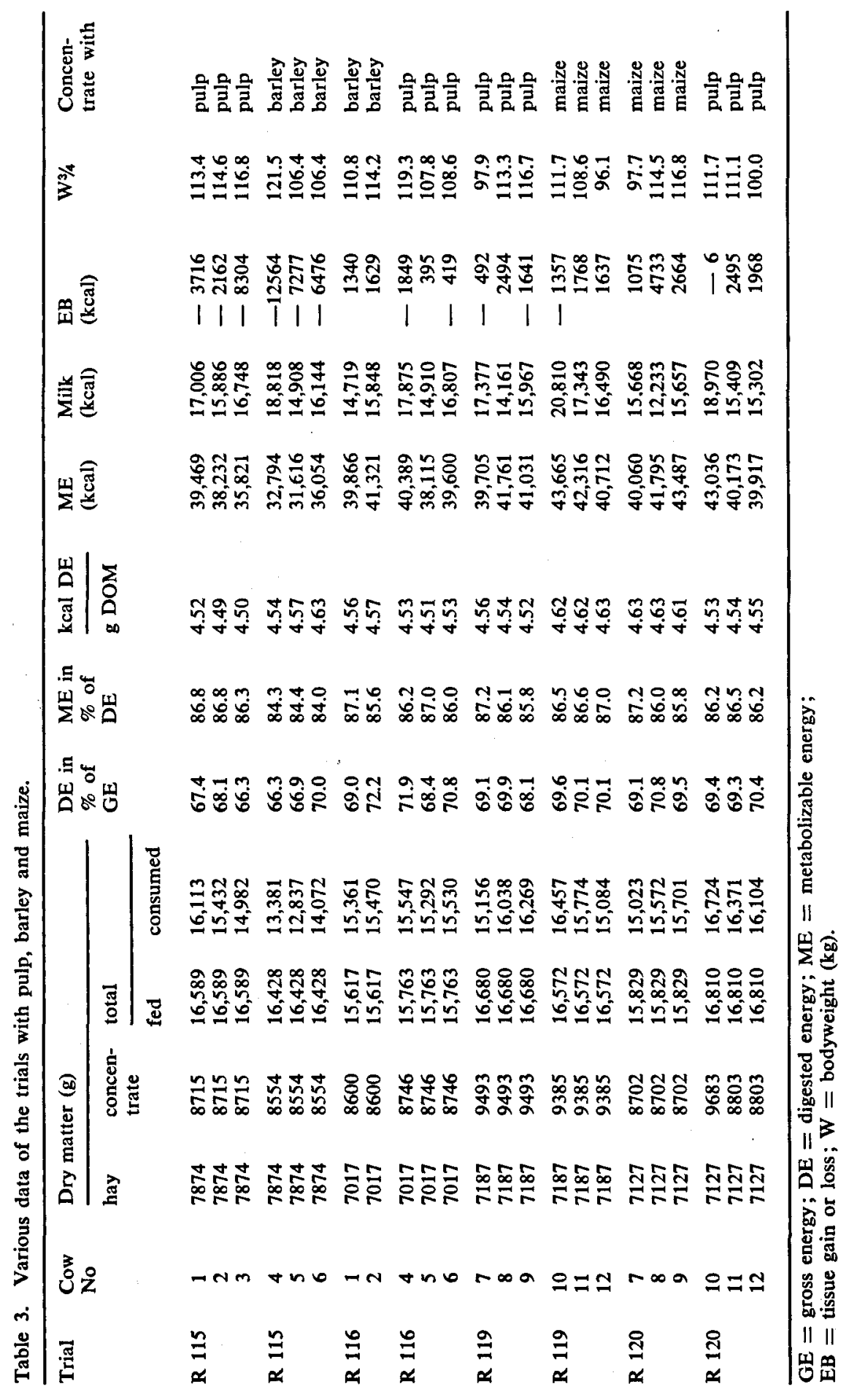




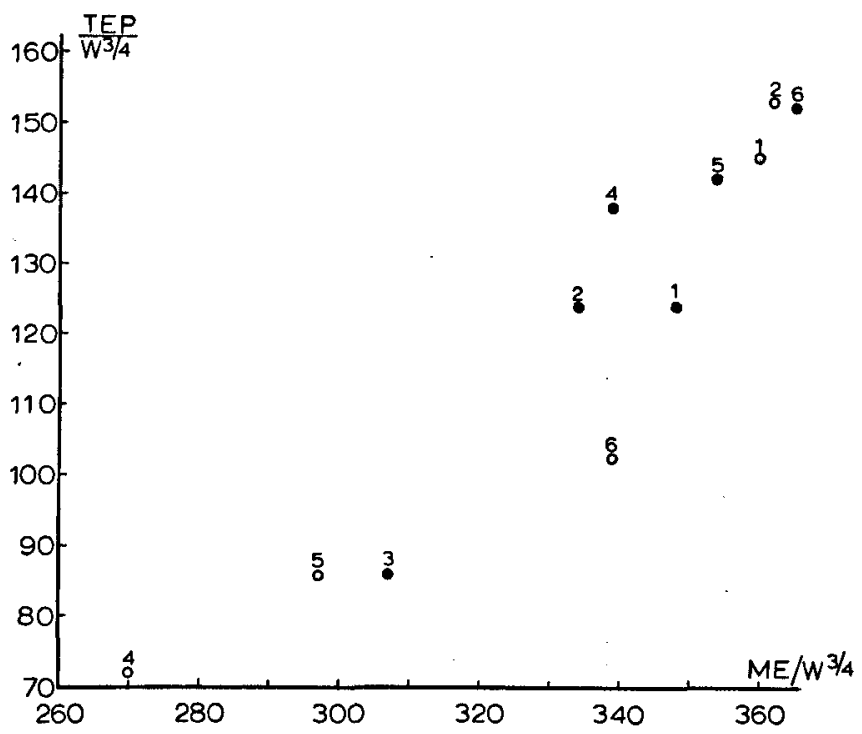

Fig. 1. Relation between total energy production (TEP/W $3 / 4)$ and metabolizable energy $\left(\mathrm{ME}^{\left.3 / W^{3} / 4\right)}\right.$ in Trial R 115/116.

- pulp ration; o barley ration; 1,2 etc. cow number.

tion for energy balance - tissue gain or loss - was applied. It was assumed that a tissue energy deposition of $1 \mathrm{kcal}$ requires as much $\mathrm{ME}$ as the production of 1 $\mathrm{kcal}$ milk. If during the trial tissue energy was lost, it was assumed that this energy was equivalent to -0.8 as much kcal milk or tissue energy (van Es et al., 1970). Thus to obtain a figure for total energy production milk energy was added to tissue energy gained or $0.8 \times$ the tissue energy lost was subtracted from the milk energy. Finally ME and total production (TEP) were divided by metabolic body weight (W3/4) with the aim to correct for differences in body weight and therefore in maintenance requirement :

$\mathrm{TEP}=\mathrm{a}\left(\mathrm{ME}-\mathrm{bW}^{3 / 4}\right) \therefore \mathrm{TEP} / \mathrm{W}^{3 / 4}=\mathrm{aME} / \mathrm{W}^{3 / 4}-\mathrm{ab}$

At increasing $\mathrm{ME} / \mathrm{W}^{3 / 4}$ values $\mathrm{TEP} / \mathrm{W}^{3 / 4}$ values increase, extrapolation towards zero $\mathrm{TEP} / \mathrm{W}^{3 / 4}$ would give an estimation of the maintenance requirement for ME per metabolic weight.

Fig. 1 shows the plotted data.

Both the data of the first and the second part do not show different relationships between these values for the two rations neither for all data together nor for those of the individual cows.

In the first part the variation is greater and the level of the TEP/W $3 / 4$ values lower, which again probably is due to the lower feed intake at the high stall temperatures.

The comparison between sugar-beet pulp and maize (Trials $R 119$ and $R$ 120; see Table 3)

In this trial $1 \mathrm{~g}$ DOM contained 4.52-4.56 kcal DE for the pulp ration and 4.61$4.63 \mathrm{kcal}$ for the maize ration. The difference was very probably caused by the higher content of fat and lower content of sucrose of the corn. The rations hardly differed 


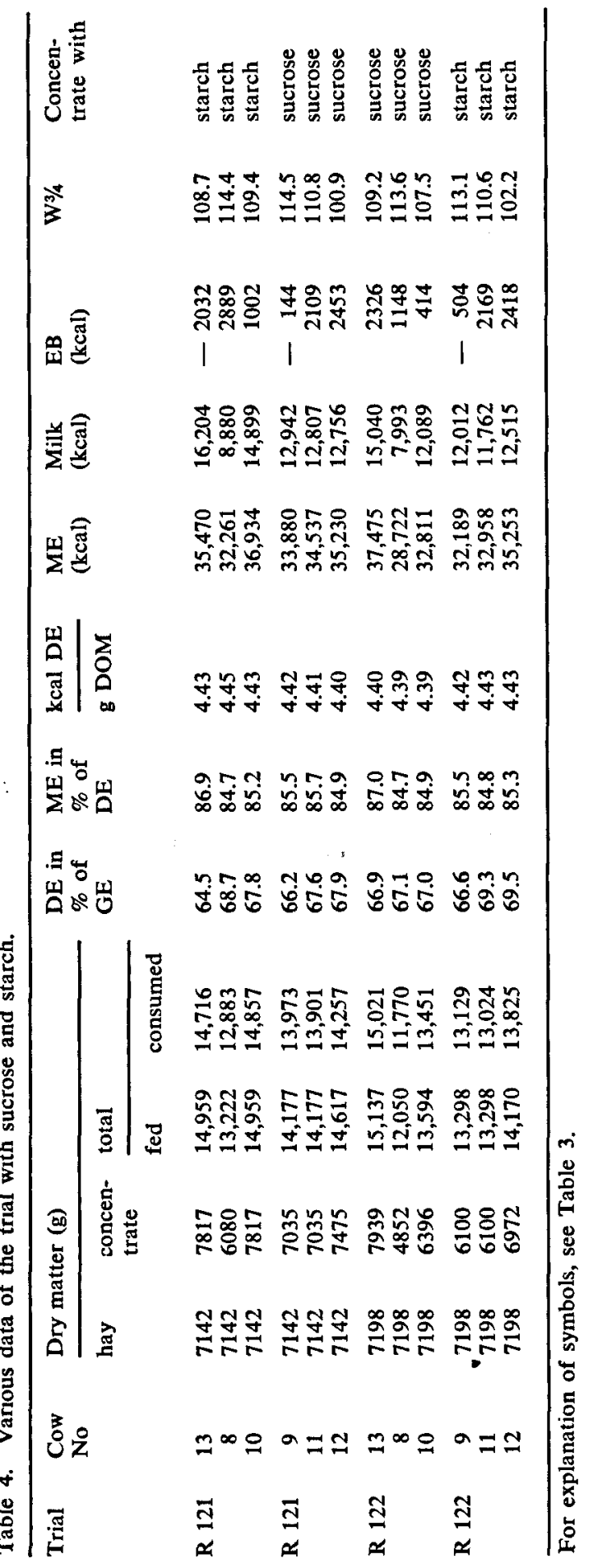




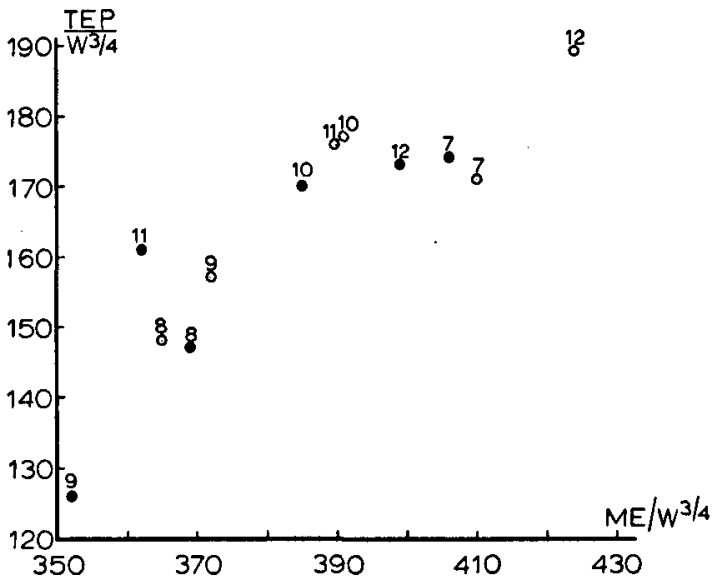

Fig. 2. Relation between total energy production (TEP/W $3 / 4)$ and metabolizable energy $\left(\mathrm{ME}^{3} / \mathrm{W}^{3} / 4\right)$ in Trial R 119/120.

- pulp ration; o maize ration; 7,8 etc. cow number.

in regard to content of $\mathrm{ME}$ in the $\mathrm{DE}: 86.6$ and $86.5 \%$. Also the relation between total energy production and ME, both expressed per metabolic body weight, did not show differences between the rations (Fig. 2).

From the two reversal trials it can be concluded that the digestible energies of pulp, barley and maize were not utilized for milk production and maintenance in a significantly different way. There probably was a slight difference in regard to the energy content of the DOM due to the differences in content of digestible crude fat and sucrose of the feeds. The TDN, Nehring's and the starch equivalent system take

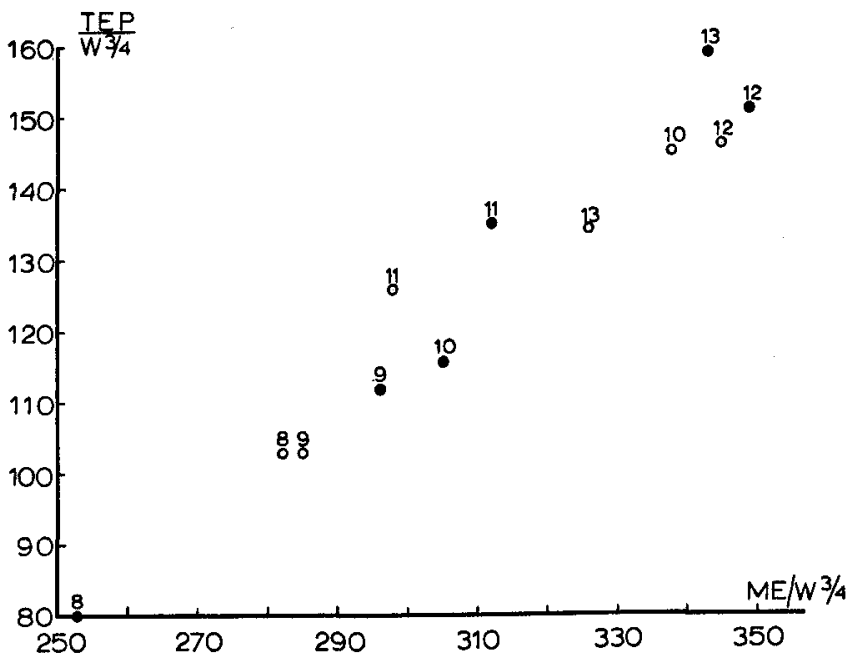

Fig. 3. Relation between total energy production (TEP/W $3 / 4)$ and metabolizable energy $\left(\mathrm{ME}^{3} / \mathrm{W}^{3} / 4\right)$ in Trial R 121/122.

- sucrose ration; o starch ration; 8,9 etc. cow number. 
account of the differences in fat content. The TDN system does not apply a correction for the lower energy content of sucrose, but this would only amount for pulp to a change from 73.3 to $72.9 \mathrm{~g}$ TDN per $100 \mathrm{~g}$. It does not apply other corrections as in view of the results of the trials for the three feeds very probably is correct. This holds also true for Nehring's system in which even a small correction for content of sucrose is made.

As to the starch equivalent system it seems correct in view of the present trials to apply a correction but only because of the $5 \%$ lower energy content of sucrose compared to starch. It, however, does not seem correct to use different value numbers for the three feeds since their DE was utilized equally efficiently.

\section{The comparison between sucrose and starch (Trials $R 121$ and $R 122$; see Table 4)}

The content of DE per $\mathrm{g}$ DOM in this trial was $4.39-4.42$ for the sucrose ration and $4.42-4.45$ for the starch ration. The small difference of about $0.7 \%$ is of the order of the size of the expected difference for rations with about $6 \%$ starch or sucrose in the DOM. The content of ME of the DE averaged $85.4 \%$ for both rations. A significant difference between the utilization of the $\mathrm{ME}$ of the two rations was not present (Fig. 3); there even was a tendency for the sucrose ration to be utilized slightly better. It is clear that it is very difficult to detect significantly the presence or absence of differences between rations differing very little in composition. Therefore, it is better not to draw a final conclusion from the present trial. This would probably be allowed after a few new reversal trials of similar character, perhaps with 12 instead of $8 \%$ sucrose and starch in the concentrate mixture, have been carried out.

\section{References}

Anonymous, 1970. Veevoedertabel van het Centraal Veevoederbureau in Nederland.

Broster, W. H., J. H. Sutton, T. Smith, V. J. Broster \& C. C. Balch, 1970. The effect of supplements of sucrose and of glucose monohydrate on the milk production and live weight of dairy cows. J. agric, Sci. 74: 217-225.

Dijkstra, N. D., 1960. De verteerbaarheid en voederwaarde van gewone en tot brokjes geperste droge pulp. Versl. Landbouwk. Onderz. 66.12.

Es, A. J. H. van, 1961. Between - animal variation in the amount of energy required for the maintenance of cows. Versl. Landbouwk. Onderz. 67.5.

Es, A. J. H. van, 1966. Labour - saving methods for energy - balance experiments with cattle; description of equipment and methods used. Neth. J. agric. Sci. 14: 32-46.

Jakobsen, P. E., 1969. Handbuch der Tierernährung, Bd. I. Parey, Hamburg/Berlin, p. 605.

Nehring, K., R. Schiemann, L. Hoffmann, W. Klippel \& W. Jentsch, 1965. Utilization of the energy of cellulose and sucrose by cattle, sheep and pigs. Proc. 3rd Symp. Energy Metabol.: 249-268.

Nehring, K., R. Schiemann \& L. Hoffmann, 1969. A new system of energetic evaluation of food on the basis of net energy for fattening. Proc. 4th Symp. Energy Metabol.: 41-50.

Schiemann, R., 1958. Kritische Betrachtungen über die Entwicklung der Stärkewertlehre Oskar Kellners. Wiss. Abh. Dt. Adad. LandwWiss. Berl. 31. 